\title{
Préface à la première édition anglaise
}

On relève fréquemment une utilisation des qualificatifs " perturbant » et " énigmatique » dans des analyses critiques de livres portant sur la résonance magnétique nucléaire (RMN). En fait, ces termes ne visent pas tant les textes eux-mêmes, mais surtout la vaste et étonnante panoplie - qui ne cesse de s'étendre - de techniques, d'applications, de séquences d'impulsions, de jargon et, bien entendu, d'acronymes qui caractérisent la spectroscopie RMN moderne. Pour bien comprendre et utiliser intelligemment la RMN de nos jours, il ne suffit plus d'être habiles dans l'interprétation des déplacements chimiques, de couplages scalaires et de schémas appelés multiplets. II faut aussi être à I'aise dans deux, trois, voire quatre dimensions, détendus quand il s'agit de conduire des expériences sur les systèmes de spin hétéronucléaires, excités par une cohérence quantique multiple et en phase quand on utilise des impulsions radiofréquences qui ressemblent à une partition d'une sonate de Beethoven. Ce livre tente d'expliquer comment certaines de ces expériences se déroulent.

$\begin{array}{rr}\text { Oxford et Exeter } & \text { P.J. H., } \\ \text { Mars } 2000 & \text { J.A. J., } \\ & \text { S. W. }\end{array}$

